\title{
Study on Methods of Sports and Military-Civilian Integration Based on College Students' Physical Fitness and Military Combat Ability
}

\author{
Xiao-nan $\mathrm{Wu}^{1} \quad$ Mei Song ${ }^{1} \quad$ Liang Zhang ${ }^{1}$
}

Training Base of School of Information and Communication, National University Defense Technology, Xi'an, Shaanxi, 706106, China

*Corresponding author. Email: 515734324@qq.com

\begin{abstract}
Under the leadership of military-civilian integration strategy, this paper presents the status quo of the development of sports and military-civilian integration at home and abroad, and analyzes the necessity of the integration and development of the two. Based on the dual demand of college students' physical fitness and military combat ability, the paper puts forward some research ideas on development of the sports and military-civilian integration. The aim is to explore approaches of military-civilian integration in college students' physical improvement and military fitness training by providing some theoretical support for the co-construction and integration of ordinary colleges and military academies.
\end{abstract}

Keywords: military-civilian integration, college students' physical fitness, military combat ability

\section{基于大学生体质和军人战斗体能的体育与军民融合思路 研究}

\author{
吴潇男 宋梅 张亮
}

${ }^{1}$ 国防科技大学信息通信学院试验训练基地, 西安, 陕西 706106, 中国 通讯作者邮箱: 515734324@qq.com

\section{摘 要}

本文基于军民融合深度发展战略思想的引领, 从大学生体质提升与军人战斗体能发展的双重需求出发, 分析了两者融合发展的必要性以及国内外体育与军民融合发展的现状, 提出了大学生体质与军人战斗 体能军民融合发展的研究思路, 旨在探索大学生体质健康与军人体能科学化训练领域的军民融合发展 路径，以期为普通高校与军事院校的共建融合发展平台提供相应的理论支撑。

关键词：军民融合，大学生体质，军人战斗体能

\section{1. 前言}

军民融合深度发展战略是习近平新时代中国特色 社会主义思想的有机组成部分。习近平多次强调, 实现 军民融合深度发展的目标就是 “努力形成全要素、多领 域、高效益的军民融合深度发展新格局”，同时提出了

“丰富融合形式、拓展融合范围、提升融合层次” 等三 个方面的基本要求。着眼我国现阶段国家发展战略、大 学生人才培养质量和军队实战化训练的现实需求, 开展
普通高校和军队院校在体育领域的融合发展研究, 是有 效提高大学生体质健康水平, 激发青年爱国主义热情, 引领有志学子积极投身国防建设事业的重要途径; 同时 也是提高军人战斗体能水平, 直接促进身体战斗能力提 升的创造性手段。本文旨在探索大学生体质健康与军人 体能科学化训练领域的军民融合发展思路, 以期为普通 高校与军事院校的共建融合发展平台提供相应的理论 支撑。 
竞技体育科学训练手段与方法的植入。2016 年我国中央 军委训练管理部训练局军事体育处虽然鼓励探索军事 体育训练科研走军民融合发展道路, 但目前缺乏开展体 育训练与科研领域的军民融合实质性实践, 相关科学论 证和社会研究仍然较少, 军民体育融合研究主要停留在 “军训” 和 “国防教育” 等层面 ${ }^{[9-11]}$ 。因此, 开展普通 高校和军队院校间体育融合研究, 建立长效机制, 尤为 迫切。

的体能, 是保证完成作战任务和完成战斗动作所需要具 备的体能。包括战斗动作中的力量、速度、耐力、灵敏、 柔韧等素质 ${ }^{[2]}$ 。

\section{3.大学生体质与军人战斗体能军民融合发展 的必要性分析}

增强大学生体质已成为提高我国人才培养质量和 发展后劲的重大课题。2018 年 9 月, 在第五次全国教育 大会上, 习近平指出: “要树立健康第一的教育理念, 开齐开足体育课, 帮助学生在体育锻炼中享受乐趣、增 强体质、健全人格、锤炼意志” ${ }^{[3]}$ 。然而, 近年来大学 生各项身体素质测试指标依然持续下降 ${ }^{[4]}$ 。积极探索提 高大学生体质的有效措施成为当务之急。

提高我国军人战斗体能, 已经成为增强国防军人战 斗力的重大课题。针对现代化军事战争, 目前我国高度 重视信息化战略手段研究和高科技武器装备研发。然而, 高技术条件下的信息化战争, 其核心要素仍然是人, 军 人战斗体能仍是战斗力构成中的核心因素, 也是未来 军事战争的重要人力基础 ${ }^{[5]}$ 。但是, 目前我国军事体育 发展正面临专业才人贵乏、科研力量薄弱、训练方法科 学性不强等亟待解决的现实问题 ${ }^{[6]}$, 军人核心战斗体能 的科学化训练和监控尚有待深入研究和综合改革。

军事体育和学校体育无论从历史渊源还是国家发 展需求的角度看, 始终是紧密联系和相辅相成的 ${ }^{[7]}$ 。军 民融合是目前解决上述问题的有效途径, 更是对国家提 出军民融合发展战略的有效落实。

\section{4.国内外体育与军民融合现状研究}

外军军事体育科研在依托军队自身科研机构的同 时, 注重与其本国体育高校和科研院所的合作。美军海 豹突击队军体训练教官是聘请地方专业机构的体育人 士担任; 瑞士、捷克、加拿大等国的军体运动科学委员 任职委员, 大多是与军方合作的高校体育教授; 芬兰于 韦斯屈莱大学体育生物部自 2005 年开始, 就与芬兰国 防部开展军事体育训练领域的科研合作, 并定期组织国 际学术论坛 ${ }^{[7]}$ 。

我国高校大学生进行军事体育训练是新时期开展 国防教育的重要举措。有助于增强大学生的国防观念、 提高身体素质、锤炼意志、提高爱国主义情怀 ${ }^{[8]}$ 。这与 学校体育的根本目标是一致的。然而, 高校大学生军事 训练仅限于新生入学的短期 “军训”, 缺乏长期效应。

我国军事院校有着系统的军事体育训练标准和体 能训练模式, 但缺乏有效的科学训练监控平台, 更缺乏

\section{5.大学生体质与军人战斗体能军民融合发展 的路径探索}

\section{1. 在教育训练理念中的融合发展}

据 1985-2008 年间 6 次全国大学生体质调查资料显 示, 各年代大学生身体素质呈下降趋势, 超重及肥胖影 响了我国大学生体质健康发展 ${ }^{[12]}$ 。特别是近年来, 我国 大学生各项身体素质测试指标持续下降, 同一项目的测 试成绩甚至还不如中学生 ${ }^{[4]}$ 。面对如此严峻的现状, 综 合考虑多方因素, 本文认为随着社会经济的快速发展, 人们生活水平日益提高, 使得生活、出行都更加的便捷、 舒适，从客观上减少了大学生日常的身体活动量; 同时 随着社会竞争压力的不断升级, 高等教育院校把师资力 量和培养重心更多的放在了文化素质教育上, 忽视了对 学生强身健体的正确引导, 没有营造出发展体育运动、 增强人民体质的健康氛围, 也没有树立身体朝气蓬勃, 思维才能高效运转的健康理念。

而部队院校始终把军事体育训练视为构成战斗力 的关键要素, 基本全年无休的开展各类体能训练, 以流 血流汗不流泪、掉皮掉肉不掉队作为拼搏口号, 通过冬 练三九、夏练三伏的坚韧磨砺, 培养出了大批的优秀军 事人才, 锻造了我军官兵钢铁般的意志品质。作为同时 代的同龄人, 用军人坚持不解的训练理念和英勇顽强的 拼搏精神去感染、鼓励、教育、引导大学生开展身体训 练, 发展强健体魄, 必将对大学生身体素质的提高和精 神面貌的改善起到积极的推动和促进作用。

\section{2. 在教育训练实践中的融合发展}

理念的融入需要平台的搭建, 将军人战斗体能的进 取精神传递给高校大学生的最好切入点是通过大学体 育教学训练的课堂实践。根据普通高校现实条件, 将军 事体育优秀科目和评价机制融入大学体育课教学和训 练中, 可以为大学生体质水平提高, 以及培养爱国主义 情操提供相应的改革思路。将军事体育训练的核心要素 和训练科目进行科学化䇻选, 结合普通高校现实情况纳 入大学体育教学内容中, 形成长效化、渐进化模式, 将 对提升大学生体质, 培养军事素养起到积极作用。

以大学体育教学训练课堂作为军事体育战斗精神 传递的实践平台, 首先要对军事院校开展的军事体育教 


\section{REFERENCES}

教学特点和适于普通高校开展的军事体育科目, 融入大 学体育课教学与锻炼中; 同时, 要根据大学生体质所涵 盖的各项素质能力, 以及普通高校大学体育课开展的硬 件条件, 选定具有针对性, 可操作性的军事体育训练科 目。随后, 根据大学生现有身体条件, 可以将确定的军 事体育科目进行简化、降难度设置, 循序渐进的提高大 学生身体素质水平和身体运动能力。为了提高大学生训 练的积极性和主动性, 在开课之初可以组织大学生到军 校观看示范表演, 在寻找自身差距的同时刺激感官认真, 激发青年血性; 在课程结束后可以组织双方进行汇报表 演、评比竞赛等促进战斗精神传承和发扬的主题活动。

\section{3. 在教育训练科研中的融合发展}

在高科技风起云涌的现代战争中, 要想打赢高技术 战争, 取得克敌制胜的主动权, 就要紧跟时代的节奏、 站在科学的前沿, 用科学合理的方法手段指导实战化训 练。在军事体育教育训练领域落实实战化的具体做法就 是用科学的理论指导训练, 用前沿的技术服务训练。然 而目前, 关于军人战斗体能的大部分研究都还停留在经 验总结的理论层面, 相关结论缺乏客观数据支撑; 实验 研究内容还不够丰富, 难以充分揭示机体在参与项目时 的人体运动规律; 研究思路还比较单一, 研究设备相对 落后, 难以深入探究解决问题的方法。

面对我国军人战斗体能训练的观念转变和现实需 求, 将专业竞技体育科学化训练理念引入军人战斗体能 作战能力训练中已然成为发展的必然趋势。在教育训练 科研领域中的融合发展, 首先需要针对军事体育训练特 点, 分析高等学校体育教学科研单位在科学训练、训练 监控的优势, 探索面向开放有效途径; 同时, 分析军事 体育针对军人战斗体能存在的问题, 包括师资队伍, 教 学训练和科研水平等。随后探寻, 依托普通高校体育教 学科研单位及体能监控平台, 将体能训练新思想、新方 法和科学化监控手段融入军事体育训练中, 为军人战斗 体能训练的科学化水平提升提供智力支持和政策依据; 以及, 依托普通高校体育教学科研机构及平台优势, 研 究科学训练理念与方法及监控手段融入军人战斗体能 训练的路径。最终, 探索出一条普通高校体能科学监控 平台与开放共享的机制与体制创新路径, 并建立其为战 斗体能训练科学化及监控服务的长效机制。
[1] Jiang Chongmin, Zhang Yimin. Process and Development Trend of Physical Research in China [J].Sports Science, 2008 (09): 25-32+88.

[2] Liu Li. Training Status and Inspiration of Combat Fitness and Combat Skills Integration [J]. Journal of Military Sports, 2016, 35(03):18-20.

[3] Gu Mingyuan. Foundation on School Physical Education for Youth[J]. Journal of Capital Institute of Physical Education, 2019, 31 (01): 9-11.

[4] Guo Jianjun, Yang Wei, Zhang Zhi. Youth Sports Blue Book: Report on China Youth Sports Development (M). Beijing: Social Science Literature Press, 2015: 1-304.

[5]Geng Kewen, Han Junhai, Zhang Hong. Study on Physical Training of Military Personnel in Information Warfare [J]. Journal of Beijing Sports University, 2007(S1):579-580.

[6] Lin Jianxuan. Strengthening the Construction of the Talent Team for Providing Human Resources for Military Sports Training [J]. Journal of Military Sports, 2015, 34(01):32-33.

[7] Zhang Zhihua. Research Features and Development of International Military Sport [J]. Journal of Military Sports, 2016,35(04):1-3.

[8] Chen Qing, Song Guangcheng. Review on Chinese School Military Training and Sports Effectiveness [J]. Journal of Wuhan Institute of Physical Education, 2016,50(01):21-26.

[9] Yang Sen, Liu Weizhong. Feasibility Study on Military Physical Education in Higher Vocational Colleges [J]. Journal of Military Sports, 2017,36(02):55-58.

[10] Chen Cen.The Interactive Development of School Physical Education and National Defense Education [D]. Chengdu Sports College, 2016.

[11] Chen Manxian, Wang Yueyue. Ideas on Improving Well-rounded College Students based on National Defense Education $[\mathrm{J}]$. School Party and Ideological Education,2018(10):82-83.

[12] Yan Xiaojian, Du Jianqiang, Ji Liu, Xiong Jianping, Ji Chengye. Study on Trend of Physical Fitness of Chinese College Students[J]. Journal of Beijing Sports University, 2012,35(09):79-84. 